\title{
Cuidados Paliativos num Hospital Universitário de Assistência Terciária: uma necessidade?
}

\section{Palliative Care in a Tertiary Assistence School Hospital: a need?}

\author{
Raphael Roncarati ${ }^{1}$; Raquel Mori Pires de Camargo ${ }^{2}$; \\ Edilaine Giovanini Rossetto ${ }^{3}$; Tiemi Matsuo ${ }^{4}$
}

\section{Resumo}

\begin{abstract}
Com o aumento de doenças crônicas e progressivas, tem se elevado o número de pacientes em estado terminal internados nos hospitais. $\mathrm{O}$ tratamento desses pacientes, que estão fora de possibilidades terapêuticas, deixa de ser curativo e passa a ser paliativo, sendo o alívio da dor um dos seus objetivos principais. Este trabalho teve o objetivo de quantificar e caracterizar os pacientes terminais internados e avaliar a satisfação desses pacientes e sua família com relação à analgesia. Os resultados da pesquisa indicam a necessidade da criação de serviços de cuidados paliativos, com equipe de profissionais da saúde especializados, na instituição do estudo, visando a qualidade da assistência aos doentes terminais e seus familiares.
\end{abstract}

Palavras-chave: Cuidados paliativos. Pacientes terminais. Dor.

\begin{abstract}
The increase of progressive and chronic diseases has elevated the number of terminal patients in hospitals. The treatment of those patients that have no therapeutic possibilities, is not curative anymore and becomes palliative, being the relief of pain one of its major goals. The purpose of this work was to quantify and qualify the terminal patients hospitalized in HURNP and to evaluate the satisfaction level of those patients and their families in relation to analgesia. The results of the research show the need for the creation of a palliative care service, with a group of specialized professionals, in the institution which is being studied, aiming at increasing the quality of assistance to the patients and their relatives.
\end{abstract}

Key words: Palliative care. Terminal patients. Pain.

\section{Introdução}

Com o desenvolvimento tecnológico e o avanço da saúde, principalmente nas áreas cirúrgica, terapêutica, de anestesia e de reanimação, têm-se tornado cada vez mais raros os casos de morte natural. Atualmente, existe um número maior de pessoas morrendo de doenças crônicas ou progressivas, aumentando o percentual de doente em estado terminal nos hospitais ou em seus domicílios (BARBOSA; VALLENTE; OKAY, 2001).

Quando todos os recursos terapêuticos curativos se encontram esgotados e quando já não há mais tempo nem a oportunidade de se fazer algo, pode-se considerar que o doente está em fase terminal. Uma

\footnotetext{
${ }^{1}$ Acadêmico do $4^{\circ}$ ano do curso de Graduação em Enfermagem e bolsista de iniciação científica da Universidade Estadual de Londrina - UEL; e-mail: raquelbb2@ @ hotmail.com. ${ }^{2}$ Acadêmica do $4^{\circ}$ ano do curso de Graduação em Enfermagem da Universidade Estadual de Londrina-UEL. ${ }^{3}$ Mestre docente do curso de Graduação em Enfermagem da Universidade Estadual de LondrinaUEL. ${ }^{4}$ Doutora docente do curso de Graduação de Enfermagem da Universidade Estadual de Londrina-UEL
} 
doença progressiva que leva à morte deve ser vista como um processo biológico e biográfico que afeta fisiológica, emocional, cultural e espiritualmente o ser humano e aqueles que mantém uma relação afetiva com ele.

Os cuidados prestados a estes doentes deixam de ser curativos e passam a ser paliativos. Segundo a Organização Mundial de Saúde (1990 apud BARBOSA, VALLENTE; OKAY, 2001), cuidados paliativos são os "cuidados totais e ativos direcionados à família e ao paciente cuja patologia não mais responde à terapêutica curativa", com a finalidade de conseguir o maior bem estar possível para o doente e sua família. A palavra paliativo vem do latim pallium, e significa manto ou cobertura. $\mathrm{O}$ cuidado paliativo estabelece uma forma de cuidado que reconhece que a cura ou o controle da patologia a longo prazo não são possíveis; promove o cuidado do paciente, acolhendo os problemas e os sintomas estressantes com a terapêutica que visa a oferecer maior conforto para o doente. Os cuidados paliativos também se relacionam com a qualidade de vida, porém não atribuem tanta ênfase à duração da vida. A esse respeito, Barbosa, Vallente e Okay (2001) acentuam que:

esse tipo de cuidado ao paciente uma vida tão ativa quanto possível, até a morte, possibilitando a ele e sua família um adequado sistema de suporte [...]. A medicina paliativa não prorroga a vida através de arsenal terapêutico, tampouco a encurta por meio de eutanásia. Tem como meta respeitar o doente e ajudá-lo a se cuidar até o final.

O conceito de cuidados paliativos teve origem no movimento hospice, proposto por Cecily Saunders e colaboradores, (apud McCOUGHLAN, 2003), os quais disseminando pelo mundo uma nova filosofia acerca dos cuidados aos pacientes terminais. Essa filosofia fundamenta-se em dois elementos fundamentais: o controle efetivo da dor e de outros sintomas decorrentes dos tratamentos em fase avançada das doenças, e o cuidado abrangendo as dimensões psicológicas, sociais e espirituais de pacientes e suas famílias. Segundo Melo (2003), com esse movimento começou a ser introduzido um novo conceito de cuidar (e não só curar), focado no paciente até o final de sua vida. Diante desse momento, um novo campo foi criado, o da medicina paliativa, incorporando essa filosofia, equipes de saúde especializadas no controle da dor e no alívio de sintomas.

Os cuidados paliativos, então afirmam a vida e encaram a morte como um processo normal, não adiam nem prolongam a morte, prevêem alívio de dor, integrando os cuidados, oferecendo suporte para que os pacientes possam viver o mais ativamente possível, ajudando família e cuidadores no processo de luto (MELO, 2003).

Os cuidados paliativos têm como uma das metas a assistência especial à dor para controlar e amenizar os prejuízos causados por ela. A dor acarreta tensão, depressão, irritação e ansiedade contribuindo para o estresse. Quando se está diante de um ser humano, como cuidadores de sua dor, temos dois fragmentos de vida que põem em presença dois seres: o que sofre e o que acolhe o sofrimento. O manejo da dor deve ser permeado por estratégias terapêuticas para um cuidado contínuo, acreditando-se nas queixas de dor do indivíduo, investigando-se sua severidade, sem a intenção de apropriação do humano, mas com o objetivo maior, o cuidar da recuperação, sem jamais perder a totalidade do ser, cuja individualidade integra o corpo, mente e espírito.

Um dos princípios dos cuidados paliativos é a atuação em equipe interdisciplinar, na qual cada profissional, respeitando sua competência, tem como meta comum o alívio do sofrimento independente da dimensão, e o preparo para a morte. Essa atuação exige que os profissionais dialoguem, respeitem-se mutuamente, e estejam preparados para partilhar suas angústias, preocupações, inseguranças e fragilidades.

Por causa da gama complexa de fatores envolvidos na experiência de sintomas físicos como os da dor, os cuidados paliativos têm como modelo de cuidado uma equipe de abordagem cujo cerne 
inclui uma enfermeira, um médico, uma assistente social, um conselheiro e um capelão (PESSINI, 2003a). A idéia de uma abordagem multidisciplinar é muito importante para os cuidados paliativos, porque implica demonstrar que nenhuma pessoa tem todas as respostas para o enfrentamento de uma determinada situação, e salienta a significância do trabalho coletivo (McCOUGHLAN, 2003). Infelizmente, ainda observamos o atendimento do paciente de forma fragmentada, mesmo com a atuação dos diversos profissionais.

Embora seja uma prática corrente em vários países, no Brasil ainda é recente o conhecimento e a prática dos cuidados paliativos, cuja difusão tem ocorrendo de forma lenta. Segundo Camponero (apud MELO, 2003), existem no Brasil cerca de 30 serviços de cuidados paliativos distribuídos nos 26 Estados e no Distrito Federal, principalmente nas capitais. Esses serviços iniciaram como serviços para controle da dor e posteriormente agregaram cuidados paliativos. $\mathrm{O}$ objetivo principal dessa iniciativa é criar as diretrizes nessa área e modelos que sejam adequados à realidade do nosso país. O Brasil é um país enorme, com peculiaridades sócio-culturais e econômicas que devem ser respeitadas, para que esses serviços possam ser efetivos em sua abordagem (MELO, 2003).

Pela crescente necessidade dos cuidados paliativos, notadamente os países desenvolvidos já começam a contar com normas e legislações específicas em relação à implementação e à organização destes cuidados. O Conselho da Europa faz um grande apelo aos países da comunidade européia para que valorizem e implementem os cuidados paliativos como proteção da dignidade da pessoa humana na sua fase terminal.

Na França, foi aprovada uma lei (n ${ }^{\circ} 99477$ de 9 de junho de 1999) acerca de cuidados paliativos, que reconhece a existência e a necessidade destes cuidados; ela atribui aos doentes terminais o direito "de ter acesso a cuidados paliativos e a acompanhamento" (art. 1.1 A); instaura para as instituições a obrigação de organizar a provisão de cuidados paliativos no seu interior ou no contexto de estruturas de cuidado alternativas à hospitalização. Além disso, essa lei aprimora a formação de profissionais da saúde nesta área e incentiva a formação de voluntariado. O desenvolvimento de políticas públicas com o objetivo de promover a humanização do atendimento, tem estimulado a criação de serviços especializados em cuidados paliativos. Um exemplo disto em âmbito nacional é a Portaria n $1.319 / \mathrm{GM}$, de 23 de julho de 2002 que cria, para o Sistema Único de Saúde, os centros de referência em Tratamento da Dor. Em nível estadual, temos como exemplo, o programa "Paraná Sem Dor de Câncer", cujo objetivo é atender de forma adequada os doentes com câncer, com dor e outros cuidados paliativos. Ainda de forma incipiente, já começam a despontar experiências-piloto de assistência embasadas na filosofia de cuidados paliativos nas instituições de saúde. A fundação da Associação Brasileira de Cuidados Paliativos (São Paulo, 1997) é uma esperança maior de operacionalização entre nós da filosofia dos cuidados paliativos (PESSINI, 2003a).

É fundamental reconhecer que se trata de um problema de saúde pública negligenciado, e para cuja implementação são necessárias três medidas: compromisso governamental; educação dos profissionais de saúde, pacientes e familiares; provisão de medicamentos essenciais.

Entre os desafios a serem vencidos para a implantação de cuidados paliativos nas instituições, mencionam-se: a ausência de uma política nacional em alívio de dor; deficiência na educação de profissionais da saúde e comunidade; preocupações quanto ao uso da morfina e outros opiáceos; limitações no fornecimento de outras drogas necessárias para o alívio da dor; deficiência na formação dos médicos, responsáveis pela prescrição de analgésicos e outras drogas; carência de recursos financeiros para pesquisa e desenvolvimento em cuidados paliativos.

A realidade é que os doentes em fase terminal ainda ocupam espaço nos hospitais gerais secundários 
e terciários. Diante da problemática, buscou-se referências que revelassem quantos são esses pacientes e quem são eles. Entretanto, verificou-se que há uma escassez de trabalhos, por ser este um tema relativamente recente em termos de produção científica.

A inexistência de programas de orientação ao tratamento dos doentes com dor crônica e carentes de cuidados paliativos, no modelo atual de atendimento à saúde, resulta em uso e gerenciamento inadequados dos recursos financeiros e humanos, como por exemplo a inadequação do uso de medicamentos específicos para o controle da dor (opiáceos e drogas adjuvantes).

O Hospital Universitário Regional do Norte do Paraná (HURNP), classificado entre os melhores hospitais do país em 2001, tem demonstrado no últimos anos a sua crescente preocupação com a qualidade dos serviços prestados, assim como a humanização do atendimento dos doentes, promovendo grande influência sobre profissionais da área de saúde que aqui realizam sua formação. Entretanto, a instituição não tem estabelecido propostas factíveis para o atendimento de cuidados paliativos, visando à consecução de melhores padrões de assistência aos pacientes com doenças avançadas e/ou terminais. Esse fato repercute qualidade da assistência e na formação dos profissionais da saúde, e é ocasionado pela ausência de campos de estágio com atividades específicas de cuidados paliativos.

Dada a inexistência de um serviço especializado em cuidados paliativos no HURNP, desconhece-se como a dor e o sofrimento desses pacientes têm sido tratados, bem como o perfil e a demanda de pacientes. Pela escassez de estudos e materiais publicados disponíveis a respeito do assunto no meio científico, fomos motivados à realização desta pesquisa. Os dados obtidos poderão também subsidiar a criação e implementação de um serviço de cuidados paliativos.

\section{Objetivos}

Identificar e quantificar os doentes com patologias avançadas e/ou terminais no HURNP; Descrever o perfil dos mesmos doentes hospitalizados no HURNP; Identificar a situação de dor e terapêutica empregada do doente em fase terminal internado no HURNP.

\section{Método e Casuística}

O presente trabalho é uma pesquisa quantitativa, e foi submetido ao Comitê de Ética em Pesquisa da Universidade Estadual de Londrina, encaminhado à Superintendência e às diretorias Clínica e de Enfermagem e, em seguida, aprovado para a realização da pesquisa.

Esta pesquisa foi realizada com todos os pacientes fora de possibilidades terapêuticas internados no HURNP e seus familiares no período de janeiro a maio de 2003, totalizando101 dias de coleta.

A pesquisa foi realizada em todas as unidades de internação, sendo elas:

- Pronto Socorro/Enfermaria - masculino e feminino.

- Pediatria.

- Moléstias Infecciosas (MI).

- Unidade Masculina e Feminina.

- Unidade de terapia intensiva (UTI I e UTI II).

Para a identificação dos doentes em fase terminal, foi investigada junto ao enfermeiro responsável por cada unidade a presença ou não destes doentes, duas vezes por semana, durante os meses citados. $\mathrm{O}$ período de 101 dias de coleta foi um tempo suficiente e expressivo para retratar uma média aproximada de ocupação de doentes em fase terminal. A investigação foi feita por dois alunos de graduação em enfermagem da Universidade Estadual de Londrina, autores desse estudo. O profissional enfermeiro foi escolhido para essa indicação pela visão geral que tem de todos os pacientes internados na unidade de sua responsabilidade e gerência além 
de ser o membro agregador da equipe de saúde dada sua permanência no cuidado com os pacientes. Conseqüentemente, é a enfermagem que permanece junto aos pacientes e familiares continuamente, sofre também desgaste emocional, por não atender às necessidades físicas, psicológicas, sociais e espirituais (RODRIGUES; ZAGO, 2003).

Os pacientes foram indicados pelo enfermeiro como prováveis pacientes terminais candidatos a cuidados paliativos de acordo com os seguintes critérios:

- presença de uma enfermidade avançada, progressiva e incurável;

- falta de possibilidades razoáveis de resposta ao tratamento específico.

O instrumento utilizado para a coleta de dados (Anexo 1) abrange itens de identificação (idade, sexo, raça, ocupação, número de dependentes, renda familiar e grau de escolaridade), itens acerca da internação (tempo, unidade e motivo da internação atual), diagnóstico médico, medicação analgésica prescrita e dados subjetivos, como a presença de dor, o tempo de diagnóstico da doença, e os cuidados no domicílio (inclusive quem os executa).

A maioria dos dados pôde ser coletada através da leitura do prontuário do paciente. Os dados subjetivos foram obtidos por entrevista com familiares, já que todos os doentes encontrados estavam impossibilitados de se comunicar devido ao rebaixamento do nível de consciência, entubação, entre outros.

Antes da realização das entrevistas, os familiares eram informados a respeito da finalidade da pesquisa e se concordassem em participar assinariam um termo de consentimento (Anexo 2) apresentado pelo entrevistador. Nenhum familiar ou paciente foi entrevistado sem que tal procedimento fosse realizado.

\section{Resultados e Discussão}

Incidência dos Doentes Necessitados de Cuidados Paliativos

Considerando todas as unidades pesquisadas, foram encontrados 39 (trinta e nove) doentes necessitando de cuidados paliativos no período total de coleta de dados, o que representa um paciente a cada dois dias e meio no hospital, uma vez que as principais unidades de internação foram incluídas no estudo.

Os 39 pacientes estavam distribuídos em várias unidades de internação, conforme a tabela a seguir:

Tabela 1. Distribuição dos pacientes terminais por unidade de internação, HURNP, 2003.

\begin{tabular}{lcc}
\hline UNIDADE & $\begin{array}{c}\mathrm{N}^{\circ} \text { DE } \\
\text { DOENTES }\end{array}$ & $\%$ \\
\hline Masculina & 11 & 28,2 \\
UTI II & 9 & 23,3 \\
PS/ enfermaria & 8 & 20,5 \\
Feminina & 6 & 15,3 \\
Moléstias Infecciosas (MI) & 4 & 10,2 \\
UTI I & 1 & 2,5 \\
Pediatria & 0 & 0 \\
\hline Total & 39 & 100 \\
\hline
\end{tabular}

A Unidade Masculina, que apresentou o maior número de doentes em estado terminal da doença, tem uma média de 66,6 pacientes/dia, o que significa, dentro do período de dados, a incidência média de um doente candidato a cuidados paliativos por semana. Já a Unidade Feminina, com média de 43,7 pacientes/dia teve aproximadamente um doente para cuidados paliativos a cada 15 dias. O Pronto-Socorro também apresenta uma proporção de aproximadamente um paciente a cada 15 dias, embora a média de pacientes/dia seja de 32. Devese considerar que o Pronto-Socorro do HURNP tem uma característica peculiar, a existência de unidades de internação masculina e feminina, com 12 leitos em cada. A UTI II possui uma média de 6,5 pacientes/dia, ou seja, uma proporção de 
aproximadamente um paciente a cuidados paliativos a cada duas semanas. Esta unidade caracteriza-se por internar a maioria dos pacientes em fase crônica da doença e apresentando microorganismos multiresistentes. Este fato tornou a coleta de dados restrita ao prontuário. A UTI I apresentou apenas um doente com necessidade de cuidados paliativos durante os meses de coleta. Pode-se explicar esta baixa incidência, por ser esta uma unidade de internação na qual a grande maioria dos doentes encontra-se em situação aguda da doença, o que demanda grandes investimentos no que se refere às possibilidades terapêuticas e ao uso da tecnologia disponível. A MI tem uma média de 13,2 pacientes/ dia, o que corresponde a aproximadamente um paciente para cuidados paliativos por mês. Na Pediatria não foi encontrada nenhuma criança sequer candidata a cuidados paliativos, visto que a equipe médica, enfermeiros e familiares têm muita dificuldade em reconhecer a situação de doença terminal em criança, uma vez que ela significa grande possibilidade de vida futura, desencadeando, portanto, diversas situações de distanásia.

Estudos recentes acerca do comportamento dos enfermeiros em relação aos doentes em fase terminal confirmam uma agressividade incontrolável ligada a vários sentimentos, entre os quais: a angústia, a vergonha e a cólera provocada pelo fracasso, entre outros (FONTES; VIEIRA; CARDOSO, 1995). O enfermeiro precisa ter clareza do significado da sua terminalidade/morte para conseguir entender e aceitar a do próximo, quando ela é inevitável. Isso requer uma reflexão acerca do valor da vida e a reflexão da morte como parte de um processo natural. A falta de compreensão da morte leva ao isolamento do paciente e família, ou do contrário, à distanásia, pois não se consegue deparar com o sentimento de impotência frente a essa situação. Na realização deste estudo, além da dificuldade em lidar com a morte, outro fato observado foi a dificuldade de os enfermeiros e a equipe médica reconhecerem o paciente necessitando de cuidados paliativos. Em alguns momentos, era preciso investigar as características do quadro do doente para a seleção dos doentes que cumpriam os critérios estabelecidos neste trabalho. Esse tipo de dificuldade, encontrada na equipe de saúde para identificar o doente em cuidados paliativos, deve-se, muitas vezes, à falta de qualificação durante a sua formação acadêmica.

Com os recursos de hoje, o médico luta denotadamente, e cada vez mais, para prolongar a vida do paciente, mesmo que isto cause mais sofrimento inútil àquela vida que já cumpriu sua missão biológica (FIGUEIREDO, 2003). Em todos os países, a filosofia e a prática da medicina curativa científica atrai os jovens, encanta os adultos, cuida das crianças e dos idosos, mas ignora os incuráveis e os moribundos. Estes seres humanos, fora dos recursos terapêuticos de cura, não despertam interesse científico e agridem os médicos que negam a morte, nela reconhecendo sua própria impotência diante do fim da vida. Acredita-se que a postura dos profissionais também possa ser decorrente da dificuldade em confrontar-se com a morte, a sua e a do próximo (RODRIGUES, ZAGO, 2003). A medicina curativa não deve ser antagônica à medicina paliativa, mas, ao contrário, elas devem ser simbióticas.

\section{Perfil dos Pacientes Necessitado de Cuidados Paliativos}

A idade média dos doentes foi de aproximadamente 64 anos, variando desde de 25 a 91 anos. A média de tempo de internação foi de 14,3 dias, sendo o mínimo de dias de internação um dia e o máximo 39 dias. De todos os doentes encontrados $51 \%$ eram do sexo masculino e $49 \%$, do sexo feminino, não havendo diferença na incidência de doentes necessitando de cuidados paliativos em relação ao sexo, dado acerca do qual não se encantraram referências na literatura. Em relação à etnia, a maioria (77\%) eram brancos, $2,5 \%$ negros e $2,5 \%$ pardos.

Alguns motivos levam estes indivíduos a procurar por internação hospitalar. Estes motivos são apresentados na tabela a seguir: 
Tabela 2. Distribuição dos motivos de internação hospitalar em doentes fora de possibilidades terapêuticas *, HURNP, 2003.

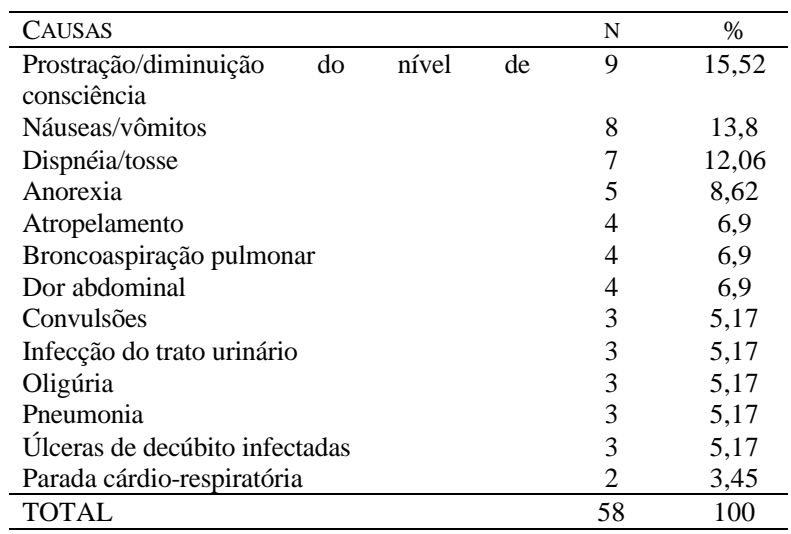

* Mais de um sintoma foi citado concomitantemente pelo mesmo doente.

Os hospitais conveniados pelo SUS não podem internar indivíduos com diagnóstico fora da possibilidade terapêutica, sendo necessário a presença de outro diagnóstico agudo para internação, que na maioria das vezes são justificados pelos sinais e sintomas que freqüentemente acometem os doentes em fase terminal, conforme demonstra a Tabela 2.

Os diagnósticos de base identificados foram:

Tabela 3. Diagnósticos mais freqüentes em doentes terminais, HURNP, 2003.

\begin{tabular}{lcc}
\hline DIAGNÓSTICO & $\begin{array}{c}\text { N. }^{\circ} \text { DE } \\
\text { PACIENTES }\end{array}$ & $\%$ \\
\hline Neoplasias & 12 & 30,76 \\
Acidente vascular cerebral (AVC)/ seqüelas & 8 & 20,51 \\
Traumatismo crânio-encefálico (TCE)/ seqüelas & 6 & 15,38 \\
Aids & 4 & 10,25 \\
Insuficiência arterial periférica crônica (IAPC) & 2 & 5,12 \\
Doença pulmonar obstrutiva crônica (DPOC) & 2 & 5,12 \\
Insuficiência renal crônica (IRC)/ hidronefrose & 2 & 5,12 \\
Abdômen agudo obstrutivo & 1 & 2,56 \\
Insuficiência cardíaca congestiva & 1 & 2,56 \\
Cirrose hepática & 1 & 2,56 \\
\hline Total & 39 & 100 \\
\hline
\end{tabular}

Conforme a Tabela 3, as neoplasias foram o diagnóstico mais encontrado nos doentes necessitados de cuidados paliativos deste estudo. Observa-se que, se somarmos os quatro primeiros diagnóstico da tabela (neoplasias, seqüelas de AVC e/ou TCE e aids) encontramos a concentração de $86 \%$ dos diagnósticos identificados.
Estima-se que cerca de 5 a 6 milhões de pessoas morrem de câncer anualmente. A OMS projeta que, pelo ano de 2020, aproximadamente $70 \%$ dos previstos 20 milhões de novos casos de pessoas diagnosticadas com câncer ocorrerão em países em desenvolvimento, principalmente em regiões onde há precárias condições de acesso aos serviços de saúde. Como consequiência desse quadro, muitas pessoas procuram os hospitais ou centros de saúde em estágio avançado da doença, quando as tentativas de cura já não são pertinentes. O alívio e o controle dos sintomas e tratamento nesta situação é a única abordagem realista e relevante, mas não é o enfoque adotado freqüentemente. Em muitos casos, particularmente nos países em desenvolvimento, os orçamentos da saúde para o cuidado e tratamento do câncer, quando existem, são insignificantes. E, com muita freqüência, esses orçamentos são gastos em tratamentos estritamente curativos, como procedimentos invasivos e dolorosos, quimioterapia e cirurgias (McCOUGHLAN, 2003).

O presente trabalho tinha como um dos objetivos caracterizar o perfil desses doentes, identificando também o número de dependentes, a renda familiar, o grau de escolaridade, quem costuma prestar os cuidados em casa e a presença ou não de dor. É de grande importância o conhecimento desses dados para a realização de uma assistência completa ao indivíduo, enxergando-o em sua totalidade física, social, familiar e espiritual Entretanto a coleta destes dados não foi possível, fato que ocorreu por vários motivos.

O primeiro deles foi o desconhecimento dos familiares a respeito do quadro clínico do doente e a situação de terminalidade. Isso impedia que os pesquisadores pudessem esclarecer os motivos da pesquisa, para que então os familiares pudessem responder aos questionamentos. Outro aspecto importante é o ético. Considerando os quatro pontos cardeais da bioética (autonomia, beneficência, nãomaleficência e justiça), sabe-se que é de direito do doente e sua família de terem todas as informações necessárias sobre a situação da doença, para poderem 
também tomar as decisões. A escassez de comunicação da equipe e é uma das queixas mais comuns de doentes e familiares (FIGUEIREDO, 2003). Os cuidados paliativos são um direito do paciente, um dever dos profissionais de saúde e não um luxo. O paciente deve ser ativo nesse processo de adoecer, assim como pode contar com o suporte familiar e a competência da equipe para que ele seja capaz de tomar suas próprias decisões (MELO, 2003).

Uma vez que a família não podia ser utilizada como fonte de dados, foi tentado o prontuário, entretanto elas não continham os dados, o que significa que os doentes não foram atendidos da maneira como deviam ter sido. É papel da enfermagem colher o histórico dos doentes, e, assim, obter informações que permitam cuidar destes indivíduos considerandoos de uma maneira completa. $\mathrm{O}$ cuidar envolve ações interativas de conhecimentos, valores, habilidades e atitudes cuja finalidade é prioritariamente aliviar o sofrimento humano, manter a dignidade e facilitar meios para controlar as crises e lidar com as experiências do viver e do morrer. É necessária uma maior humanização do serviço, para que o paciente não morra envolto em dor e sofrimento (CARVALHO, 1999). O ideal a ser atingido para a área de assistência à saúde é desenvolver uma consciência da importância do cuidar, principalmente quando curar não é mais possível (GUERRA apud PESSINI, 2003b).

Outro motivo que pode ter dificultado a realização deste estudo é a formação inadequada dos profissionais, que, muitas vezes, têm dificuldade em lidar com a situação de morte, e preferem isolar-se a relacionar-se com o próprio doente e família. Em algumas escolas no Brasil, ainda não se discute o tema cuidados paliativos. Esse fato já foi comprovado culturalmente, pois nos países do ocidente, nega-se a morte e até a velhice, as pessoas envolvem-se no sonho da eterna juventude e saúde, em que a morte não tem lugar e deve ser escondida (McCOUGHLAN, 2003). A educação continuada dos profissionais de enfermagem, relativa aos pacientes em estágio terminal, deve prevalecer no planejamento da instituição, considerando o desconhecimento não só das ações de enfermagem em cuidados paliativos, mas da filosofia dos cuidados paliativos (RODRIGUES; ZAGO, 2003). Essa talvez pode ser uma maneira de melhorar-se o atendimento aos doentes em fase terminal da doença.

\section{A Dor nos Pacientes Necessitados de Cuidados Paliativos}

Para avaliar a situação de dor desses doentes, o prontuário era consultado quanto ao relato de dor pelo doente e a medicação analgésica prescrita, bem como seu esquema. Entre os doentes encontrados, 95\% tinham apenas Dipirona endovenosa prescrita, dos quais $78,4 \%$ estavam prescritos no esquema "se necessário" e o restante $(21,6 \%)$ prescritos com horário fixo. Apenas dois doentes faziam uso de opióide fraco, em horários regulares e dois pacientes usavam opiódes fortes em horário fixo. Outras drogas foram encontradas que podem ter sido utilizados ou não como adjuvantes para o alívio da dor, como analgésico comum, antiinflamatórios esteróides e anticonvulsivantes. Não havia registro de dor referida pelos doentes, uma vez que eles se encontravam impossibilitados de comunicar-se verbalmente e a instituição não utiliza escalas para avaliação sistemática da dor.

A dor é uma das queixas mais comuns nos doentes terminais considerada e, pelo sofrimento que causa o paciente e a família, é considerada como alvo principal a ser atingido, sobretudo nos casos de câncer e AIDS. Trata-se, pois, de um problema significativo, que requer a intervenção da Enfermagem.

Smith (apud PESSINI, 2003b) afirma que nos EUA mais de $50 \%$ dos pacientes com câncer terminal tiveram sofrimento físico durante os últimos dias de sua vida, e ele foi aliviado (quando o era) só por sedação. Naquele país em torno de $40 \%$ de todos os pacientes que estão expirando morrem com dor.

A dor e o sofrimento não tratados são o grande desafio a ser trabalhado e um dos objetivos centrais 
da filosofia do hospice. Dor aguda e crônica são freqüentes na doença oncológica e, na forma crônica, ela ocorre em mais de 2/3 dos doentes. A experiência dolorosa desse doente é descrita como "dor total", que é a expressão do conceito de que ao ser humano é impossível interpretar apenas o aspecto nocicepção da dor (quantidade de tecido lesado) (PIMENTA, 2003). A dor no doente oncológico reveste-se de características especiais. É freqüentemente de intensidade significativa, manifesta-se em mais de um local, e é diária, quando não se manifesta de forma continuada, durante várias horas do dia (PIMENTA, 2003).

O uso da Dipirona como droga de única escolha não tem sido a prática utilizada para os casos de pacientes com doenças terminais, porque ela não tem sido capaz de promover o alívio da dor de forma eficaz. Isso ocorre, sobretudo, devido à grande presença do esquema "se necessário", uma vez que o doente só será medicado ou se verbalizar sua dor, o que não aconteceu com a totalidade dos doentes encontrados. É importante valorizar a dor que o paciente diz sentir. Entretanto todos os pacientes investigados encontravam-se sem condições de verbalizar sua dor, caso ela estivesse presente. $\mathrm{Da}$ mesma forma, na administração dos analgésicos, o enfermeiro deve reconhecer: a ação das drogas; as vias de administração, com prioridade para a via oral e subcutânea; os horários, que devem ser regulares e não só "se necessário", (ou seja, quando o paciente informa sentir dor); a dose adequada e os efeitos colaterais, para que ela, na impossibilidade da prevenção, possa ser evitada ou tratada(RODRIGUES; ZAGO, 2003).

Considerando que a maioria dos medicamentos essenciais para o alívio da dor e controle de sintomas não são excessivamente caros e podem estar disponíveis na maioria dos países (McCOUGHLAN, 2003), acredita-se não ser este o motivo para a baixa incidência do uso da medicação analgésica. $\mathrm{O}$ Instituto de Medicina, recentemente, descobriu que de 40 a $80 \%$ dos pacientes com doença terminal relatam que seu tratamento da dor é inadequado e prolonga a própria agonia da morte (SMITH apud PESSINI 2003b).

Aliviar a dor é e sempre foi inerente ao "fazer" da medicina e da enfermagem. Cuidar, educar, acolher, amparar, aliviar desconfortos, controlar sintomas e minimizar o sofrimento são ações cotidianas na vida dos profissionais (PIMENTA, 2003).

\section{Conclusão}

No período de coleta, foram encontrados 39 doentes candidatos a receberem cuidados paliativos por estarem em fase terminal da doença e/ou fora de possibilidades terapêuticas, o que significa um doente a cada dois dias e meio. Desses doentes, a maioria $(28,2 \%)$ estava internada na Unidade Masculina, seguida da UTI II, Pronto-Socorro e Unidade Feminina. Das unidades pesquisadas, as que tiveram uma menor incidência de doentes candidatos a cuidados paliativos foram a UTI I, com apenas um doente durante todo o período de coleta, e a Pediatria, na qual a equipe de saúde não apontou uma criança sequer que estivesse fora de possibilidades curativas.

Verificou-se, durante a realização da pesquisa, que a equipe de saúde tem grande dificuldade em reconhecer um doente candidato a receber cuidados paliativos. Os motivos dessa dificuldade são a falta de preparo dos profissionais de saúde, durante a formação acadêmica, para a abordagem desse tipo de cuidados, o desconhecimento acerca da filosofia dos cuidados paliativos, a dificuldade em lidar com a situação de morte, o desconhecimento das famílias sobre a terminalidade de seu ente e a falta de registros nos prontuários, tanto na identificação do doente, quanto na presença de dor.

Quanto ao perfil desses doentes, a idade média foi aproximadamente 64 anos, variando desde 25 a 91 anos. A média de tempo de internação foi de 14,3 dias, sendo que o mínimo de dias um, e o máximo 39. Não houve diferença significativa na incidência de acordo com o gênero, sendo $51 \%$ do sexo 
masculino e $49 \%$ do sexo feminino. Com respeito à etnia, a maioria (77\%) era branca.

Os motivos mais freqüentes pelos quais os doentes são levados à internação são os seguintes: prostração e/ou diminuição do nível de consciência, náuseas/ vômitos, dispnéia/tosse, anorexia entre outros.

Os diagnósticos de base mais encontrados foram: neoplasias (12 casos), AVC/ seqüelas (8 casos), $\mathrm{TCE} /$ sequielas ( 6 casos) e aids ( 4 casos), entre outros menos freqüentes.

Quanto à dor, entre os doentes encontrados, 95\% deles tinham apenas Dipirona endovenosa prescrita para alívio da dor, dos quais $78,4 \%$ estavam prescritos em esquema "se necessário" e o restante $(21,6 \%)$ prescritos com horário fixo. Apenas dois doentes faziam uso de opióide fraco, em horários regulares e dois doentes usavam opióides fortes em horário fixo. Nenhum registro ou observação de dor foi encontrado nos prontuários.

\section{Considerações Finais}

A curiosidade acerca da incidência e o perfil dos doentes terminais que estão internados no HURNP, bem como o tratamento que têm recebido, motivou a realização deste estudo. Há uma escassez de materiais sobre o assunto e esta pesquisa foi pioneira na instituição.

Vários desafios foram encontrados e tiveram de ser enfrentados, como a dificuldade na coleta de dados, o desconhecimento dos profissionais de saúde acerca do tema e, principalmente, o reconhecimento de que os doentes em fase terminal da doença e seus familiares não têm recebido um tratamento humanizado e especializado.

Quanto mais se avança nas tecnologias dentro da área da saúde, mais se acredita que é possível afastar a morte de dentro das instituições. É possível realizar a cura em diversas situações, porém não se pode atuar em nossa finitude e mortalidade. Assim, faz-se necessária a inclusão de serviços de cuidados paliativos, levando-se em conta a demanda encontrada e o provável tratamento inadequado dos doentes. Sugere-se, então, a criação de uma unidade específica para cuidados paliativos na instituições, além de ambulatório especializado. É necessária, também, uma equipe de saúde específica e itinerante, que esteja capacitada para atuar nas diversas áreas, inclusive nos domicílios, fornecendo informações e apoio, sobretudo em questões como o alívio da dor e oluto.

Finalmente, o que importa é que estes doentes e suas famílias precisam ser melhor atendidos e terem suas necessidades satisfeitas. Essas medidas propiciariam autonomia para tomada de decisões referentes a seu tratamento e ajudariam estas pessoas a viver e enfrentar o morrer da melhor forma possível.

\section{Referências}

BARBOSA, S. M. M; VALLENTE, M. T.; OKAY, Y. Medicina Paliativa: a redefinição da experiência humana no processo de adoecer. Revista da Sociedade Brasileira para o estudo da dor, São Paulo, v.3 , n.2, p.61-68, abr.l mai./jun. 2001.

CARVALHO, M. V. B. O cuidar do ser humano e o assistilo em face da dor oncológica. Dor em Foco, São Paulo, ano 2, n.4, p.6-7, 1999.

FIGUEIREDO, M. T. A. Educação em cuidados paliativos: uma experiência brasileira. O mundo da Saúde, São Paulo, ano 27, n.1, v.27, p. 165-170, jan./mar. 2003.

FONTES, F.; VIEIRA, J. L.; CARDOSO, L. P. O enfermeiro perante a morte. Revista Técnica de Enfermagem, Rio de Janeiro, ano 7, n.85, fev. 1995.

LEMONICA, L. Dor no Brasil é subtratada. Dor em Foco, São Paulo, ano 1, n.4, p.4-5, 1998.

McCOUGHLAN, M. A necessidade de cuidados paliativos. O mundo da Saúde, São Paulo, ano 27, n.1, v.27, p.6-14, jan./mar., 2003.

MELO, A. G. C. Os cuidados paliativos no Brasil. O mundo da Saúde, São Paulo, ano 27, n.1, v.27, p.58-63, jan./mar., 2003.

PESSINI, L. A filosofia dos cuidados paliativos: uma resposta diante da obstinação terapêutica. $O$ mundo $d a$ Saúde, São Paulo, ano 27, n.1, v.27, p.15-31, jan./mar., 2003a. 
PESSINI, L.; CAPONERO, R.; MELO, A. G. C. Cuidados paliativos: uma necessidade urgente na área de saúde. $O$ mundo da Saúde, São Paulo, ano 27, n.1, v.27, p.3-6, jan./ mar., 2003b.

PIMENTA, C. A. M. Dor oncológica: bases para avaliação e tratamento. O mundo da Saúde, São Paulo, ano 27, n.1, v.27, p.98-110, jan./mar., 2003.

RODRIGUES, I. G.; ZAGO, M. M. F. Enfermagem em cuidados paliativos. $O$ mundo da Saúde, São Paulo, ano 27, n.1, v.27, p.89-92, jan./mar., 2003.
ROSSETTO, E. G.; DELLAROZA, M. S. G.; KRELING, M. C. G. D.; CRUZ, D. A. L.; PIMENTA, C. A. M. Epidemiologia da dor em crianças, adultos e idosos. Arquivos Brasileiros de Neurocirurgia, São Paulo, v.18, n.4, p.213-224, 1999.

ROSSETO, E. G et.al. Programa para o Diagnóstico da Assistência ao paciente com dor no HURNP. Londrina: UEL, 2001. 15p. 
